\title{
Nuevos lineamientos en la evaluación integral del adulto mayor
}

Estimado editor,

Hemos leído con atención el artículo “Calidad de vida en adultos mayores de Guerrero, México” publicado en esta revista. El blasón del autor es, sin duda, el análisis riguroso que genera a la hora de determinar la asociación de variables relacionadas a la calidad de vida del adulto mayor, siempre orientado a fomentar políticas públicas que favorezcan una perspectiva de salud positiva; así mismo, en vista de la escasez de estudios en esta área, destacamos la audacia del autor al atreverse a divulgar este asunto de interés colectivo que nos permitirá mantener la autonomía y la calidad de vida de los adultos mayores en el mundo.

Queremos empezar resaltando la evolución del paciente geriatra a lo largo de los años, desde que nace y se forma en sociedad: como una persona que se añade paradigmas, se refugia en una vida espiritual y recrea dilemas ético-morales (que lo acompañarán hasta sus últimos días e influirán en sus decisiones); y en la perspectiva que tenga con respecto a su realidad. Los profesionales de la salud, al referirse a un paciente geriátrico, saben que se trata de un individuo con pluripatología (atípicas en su mayoría) y polifarmacia, susceptible a yatrogenia y negligencias; de ahí la importancia de estudiar a este sector de manera ordenada, y, si se quiere, estructurada. No es difícil evidenciar el mayor desafío para la sociedad científica que representa el relacionar: la heterogeneidad propia del moldeamiento social cronológico (el paciente como ser humano); su entorno (familiar y estatal, facilitador o no de bienestar); y su condición como paciente. No obstante, la mayoría de estudios se limitan a comparar unas pocas variables que, si bien nos aproxima a un mayor entendimiento, arrojan resultados bastante subjetivos. Se sustrae, entonces, la pregunta fundamental: ¿Cuál es la manera más adecuada de abordar a este sector, de tal manera que goce de una intervención especializada y adaptable?

Con el fin de amenizar esta tarea, y a diferencia de otros estudios que abordan de manera individual sólo algunos aspectos que componen la vida propia, proponemos evaluar los tres antes mencionados que determinan, sin duda, la vida humana. De esta manera procedemos a delinear nuestros ejes centrales entorno a la calidad de vida en el adulto mayor:

1. La heterogeneidad propia del moldeamiento social cronológico

Consideramos la evaluación de las siguientes variables: convivencia con familiares, institucionalidad, actividad física, nivel educativo, sentimiento de abandono por parte de la familia, patologías (de larga y corta duración), medicamentos que consume, discapacidad (parcial o total), bienestar espiritual, estado civil, dependencia (leve, moderada, severa). En relación a su fuente de sostenimiento se deben considerar sus ingresos económicos y la fuente de ingresos (familia, trabajo, jubilación, subsidios, etc.).

2. El entorno

En el informe de la doctora Margaret Chan, "Informe mundial del envejecimiento y la salud", publicado en el año 2015, se enfatizan las consecuencias sanitarias que representarían también un problema para los sistemas sanitarios, su personal y su presupuesto, ello involucraría el envejecimiento poblacional; señala, además, que los desafíos planteados en el presente siglo deben ser afrontados con presura(1). Las variables a evaluar son: Servicios de salud, actividades recreativas, residir en medio urbano, sentimiento de protección estatal, asistencia social.

3. Condición como paciente

Se realizó en Colombia un estudio descriptivo que toma como muestra a 384 adultos mayores; en él, Guerrero y Yépez (2015) concluyen que los factores de riesgo que los hacen más vulnerables son: el vivir en regiones con bajos ingresos económicos, residir en zonas social y geográficamente aisladas, no contar con la compañía de una persona para su cuidado, y padecer hipertensión arterial(2).

Esta última variable propuesta es confirmada por dos estudios, el primero: "Calidad de vida en adultos mayores en Cartagena, Colombia” publicado en la Revista de Salud Pública en el año 2017. En él se encuentra que, entre las patologías más frecuentes presentadas en los 657 adultos mayores evaluados, 
predominaron las de origen cardiovascular $(26,1 \%)^{(3)}$. En el segundo, Valdez-Huirache y ÁlvarezBocanegra encuentran que, de los 368 adultos mayores evaluados, el 31,3\% presentó hipertensión arterial como comorbilidad(4). Se examinarán en este punto las siguientes variables: edad, sexo, capacidad funcional, cuenta con Sistema Integral de Salid (SIS), percepción de la asistencia sanitaria, tiempo de enfermedad, dependencia para realizar sus actividades cotidianas.

Se deberá, entonces, realizar una clasificación sindrómica con el fin de aproximarnos a una realidad más fiel que contextualice al paciente geriátrico en ese momento de su vida; además, sugerimos la creación de escalas para cada uno de los tres tópicos mencionados que cuenten con una asociación e influencia prudentes entre las variables. El orden de evaluación consistirá, en todo momento, en establecer primero los "síndromes geriátricos" para posteriormente someterlos a evaluación en las distintas escalas, de tal manera que, reducimos la población geriátrica en subgrupos que nos permitan intervenir de manera más exclusiva e integral.

Para finalizar, cabe destacar que no es lo mismo abordar a un adulto mayor proveniente de un país subdesarrollado que a un adulto mayor proveniente de un país desarrollado; no debemos caer en la dependencia intelectual, las realidades son totalmente distintas, así como el modo que tiene cada paciente geriátrico de representar su mundo individual como reflejo de las condiciones en las que vive. De ahí que debemos cuidarnos de importar teorías, y, en lugar de ello, generar un sello adaptado a nuestra realidad, propio, de manera que podamos divisar el panorama vigente desde esta nueva perspectiva.

Jonathan Jesús Benites-Cuadros ${ }^{*}$ orcid.org/0000-0001-9943-6784 Aarom Raúl Salazar-Ormeño ${ }^{1}$ orcid.org/0000-0001-8800-3940 Samanta Picón-Flores ${ }^{1}$ orcid.org/0000-0002-9595-3052

1. Escuela de Medicina Humana, Facultad de Ciencias de la Salud, Universidad Privada Norbert Wiener. Lima, Perú

Conflictos de interés: No declaran.

*Autor de correspondencia Jonathan Jesús Benites-Cuadros e-mail: jbenitescuadros@gmail.com

\section{Referencias}

1. Varela Pinedo LF. Salud y calidad de vida en el adulto mayor. Revista Peruana de Medicina Experimental y Salud Pública. 2016;33(2):199-201. Disponible en: http://www.scielo.org.pe/scielo.php?script=sci_arttext\&pid=S172646342016000200001

2. Guerrero N, Yépez MC. Factores asociados a la vulnerabilidad del adulto mayor con alteraciones de la salud. Univ. Salud. 2015;17(1):121-131. Disponible en: http://www.scielo.org.co/scielo.php?pid=S012471072015000100011\&script=sci_abstract\&tlng=es

3. Vargas-Ricardo SR, Melguizo-Herrera E. Calidad de vida en adultos mayores en Cartagena, Colombia. Rev Salud Pública. 2017;19(4):549-554. Disponible en: http://www.scielo.org.co/pdf/rsap/v19n4/0124-0064-rsap-19-04-00549.pdf

4. Valdez-Huirache MG, Álvarez-Bocanegra C. Calidad de vida y apoyo familiar en adultos mayores adscritos a una unidad de medicina familiar. Revista Horizonte Sanitario. 2018;17(2):113-121. Disponible en: http://www.scielo.org.mx/scielo.php?script=sci_arttext\&pid=S2007-74592018000200113 